\title{
ASESMEN INSTALATUR LISTRIK BERBASIS KEBUTUHAN INDUSTRI JASA KONSTRUKSI KETENAGALISTRIKAN
}

\author{
${ }^{1)}$ Sukardi, ${ }^{2)}$ Soenarto \\ ${ }^{1)}$ Universitas Negeri Padang, ${ }^{2}$ Universitas Negeri Yogyakarta \\ ${ }^{1)}$ sukardi@,ft.unp.ac.id, ${ }^{2)}$ soenarto@uny.ac.id
}

\begin{abstract}
Abstrak
Penelitian ini bertujuan menghasilkan asesmen instalatur listrik (AILIS) berbasis industri jasa konstruksi ketenagalistrikan. Penelitian AILIS dikembangkan melalui tiga tahap, yaitu: desain atau perencanaan, uji coba terbatas, dan uji coba diperluas. Tahap desain meliputi: kegiatan prasurvei, studi hasil-hasil penelitian, analisis masalah, dan analisis kinerja instalatur listrik. Kegiatan tahap uji coba terbatas meliputi: validasi pakar dan pengguna, analisis dan revisi. Uji coba diperluas meliputi: pengumpulan data, analisis, revisi, dan diseminasi. Data penelitian dikumpulkan dengan menggunakan instrumen berupa angket dan lembar observasi. Subjek uji coba berjumlah 210 responden para manajer perusahaan industri usaha jasa konstruksi ketenagalistrikan di Provinsi Sumatera Barat. Teknik analisis data untuk memvalidasi bahwa AILIS yang dihasilkan fit digunakan confirmatory factor analysis $(C F A)$. Hasil penelitian menyimpulkan AILIS sangat baik untuk mengakses kinerja instalatur listrik industi usaha jasa konstruksi ketenagalistrikan, dengan indikator perancangan instalasi listrik, pengkonstruksian instalasi listrik, komisioning instalasi listrik, pengoperasian, dan pemeliharaan instalasi listrik.
\end{abstract}

Kata kunci: asesmen, confirmatory factor analysis, instalatur listrik

\section{AN ASSESSMENT OF ELECTRICITY CONSTRUCTION BASED ON THE NEED OF SERVICE INDUSTRY OF ELECTRICAL INSTALLER}

\author{
${ }^{1)}$ Sukardi, ${ }^{2)}$ Soenarto \\ ${ }^{1)}$ Universitas Negeri Padang, ${ }^{2}$ Universitas Negeri Yogyakarta \\ ${ }^{1)}$ sukardi@ft.unp.ac.id, ${ }^{2)}$ soenarto@uny.ac.id
}

\begin{abstract}
The aim of this research was to produces an assessment of electricity construction service industrial needs-based electrical installer (AILIS). The research was developed through three stages, namely: the design, the limited trial, and expanded trials. The design consists of: presurvey, studies on the research findings, problem analysis and analysis of electric installer performance. The limited trial included: validation of the AILIS through expert judgment and the user, analysis and revision. The expanded trial included: data collecting, analysis, revision, and dissemination. The research instruments consisting of a questionnaire and observation sheets were distributed to capture the data needed for the analysis. The subjects for the implementation were 210 respondents as the managers of electricity construction service industrial companies in West Sumatra Province. The CFA was used to verify that the developed model fit the AILIS. The finding shows that AILIS is excellent at assessing electrical installer performance in the electricity construction service industry, with indicator the design of electrical installation, the construction of electrical installation, the commissioning of electrical installation, the operation, and the maintenance of electrical installation.
\end{abstract}

Keywords: assessment, confirmatory factor analysis, electrical installer 



\section{Pendahuluan}

Upaya pembangunan sistem ketenagalistrikan Indonesia saat ini berada pada perbaikan dan peningkatan kemudahan konsumen listrik mendapatkan akses pelayanan sambungan baru melalui telepon. Devan (2013, p.64) mengemukakan, "In Indonesia in 2011 the utility PT. PLN (Persero) set up a call center enabling customers to request a new electricity connection by phone. It further simplified the application process by eliminating the requirement to bring in a copy of a neighbor's bill to belp determine the exact address of the new customer's business". Kesederhanaan proses aplikasi memperoleh sambungan baru tersebut serta merta membutuhkan performa instalatur listrik (electrician) yang berkualitas. Instalatur listrik yang berkualitas, dapat diperoleh melalui asesmen kinerja (performance assessment) yang sistematis, teratur, objektif, dan sesuai dengan kriteria serta standar.

Obisi (2011, p.92) menyatakan bahwa efektivitas dan efisiensi kinerja karyawan tercapai jika individu atau karyawan tersebut terus dinilai dan dievaluasi. "Organizational performance and its resultant efficiency and effectiveness can only be achieved when individuals are continuously appraised and evaluated". Mardapi (2008, p.5) menjelaskan "Penilaian atau asesmen mencakup semua teknik yang digunakan untuk menilai unjuk kerja individu (berfokus pada individu)". Ketidakmampuan menerapkan strategi penilaian kinerja (performance assessment) yang efektif dan efisien, akan menghalangi perusahaan mencapai keunggulan kompetitif.

Wynne (2008, p.1) menyatakan bahwa "Assessment is the practice of collecting information about persons progress". Penilaian adalah praktik mengumpulkan informasi tentang kemajuan seseorang atau individu. Barbara (2010, p.3) menjelaskan bahwa assessment is composed of three steps (1) goals (may also be called outcome or objectives), (2) information (may be called measures or evidence), and action (using the information may be called closing the loop). Uraian ini menyatakan bahwa asesmen dapat dilakukan dengan tiga tahapan yakni menetapkan hasil yang diperoleh pada kegiatan asesmen, bukti dan tindak lanjut dari kegiatan asesmen.
Berry (2011, p.32) menjelaskan bahwa "Assessment is one of the most emotive words in the education lexicon. It has a variety of connotations for different people anxiety, competition, success, feedback, to mention but a few depending on the nature of their participation in the assessment process". Asesmen memiliki berbagai konotasi, ada yang beranggapan tekanan, kompetisi, keberhasilan, umpan balik, standar, dan membosankan, hal ini tergantung pada sifat dan partisipasinya dalam proses asesmen.

Elaine (2004, p.18) mengemukakan bahwa " $\mathrm{A} n$ advantage of using different rating sources is that they often have different views of an employee's performance and thus provide a more complete picture of effectiveness. Asesmen yang komprehensif dari kinerja karyawan, praktisi berpengalaman telah ditemukan asesmen yang meyakinkan dan cenderung dipandang lebih kredibel untuk berkomunikasi dengan kebutuhan pembangunan organisasi. Keuntungan penggunaan sumber peringkat yang berbeda, karena penilai sering memiliki pandangan yang berbeda pada kinerja karyawan. Laporan hasil penilaian kinerja karyawan dapat langsung menjadi sumber yang sangat baik untuk jenis informasi kinerja karyawan.

Padmadewi (2005, p.456) menyatakan bahwa "Asesmen diartikan sebagai prosedur yang digunakan untuk mendapatkan informasi tentang prestasi atau kinerja seseorang yang hasilnya akan digunakan untuk evaluasi”. Asesmen instalatur pada penelitian ini adalah kegiatan penilaian terhadap kinerja instalatur listrik di industri jasa konstruksi ketenagalistrikan.

Messah (2011, p.26) menyatakan bahwa "The research revealed that competence, assessment and development affected employee performance to a moderate extent as indicated by $56.9 \%$ of the respondents. There were also a number of number of statements on competence, assessment and development that enhanced employee performance as indicated by the respondents". Sangat besar pengaruh penilaian kinerja karyawan yang dilakukan secara kontinu terhadap kinerja perusahaan. Asesmen unjuk kerja karyawan yang dilakukan secara terus menerus, mampu menumbuhkan motivasi kerja berpresta- 
si dan memunculkan tingkat kompetitif yang bermanfaat.

Aktivitas asesmen instalatur listrik oleh pejabat teknik dan direktur industri jasa ketenagalistrikan secara kontinu, dapat menjamin tersedianya energi listrik yang berkualitas. Karena asesmen tersebut mampu meningkatkan kualitas kinerja (performance) instalatur listrik. Adnan Ahmed (2010, p.62), Obisi (2011, p.92), Messah (2011, p.16), Idemobi (2011), Leila (2011, p.1761), Lee (2000, p.420), Lynn (2005, p.23), dan David (2006) telah meneliti tentang performance assessment of employer. Hasil penelitian menyimpulkan bahwa penerapan performance assessment of employer di perusahaan yang dilakukan secara kontinu, mampu meningkatkan kinerja karyawan dan kinerja perusahaan. Semua hasil penelitian, menyatakan bahwa penerapan performance assessment di industri atau perusahaan, secara positif meningkatkan kinerja karyawan dan berakibat pada kepuasan konsumen serta berdampak langsung pada peningkatan kinerja dan pengembangan industri atau perusahan.

Rekomendasi beberapa penelitian yang relevan tersebut menunjukkan bahwa asesmen instalatur listrik oleh pejabat teknik dan direktur industri jasa ketenagalistrikan sangat urgen diterapkan di industri jasa konstruksi ketenagalistrikan. Kegiatan asesmen kinerja instalatur listrik secara kontinu dapat meningkatkan kinerjanya dan menghasilkan ketenagalistrikan yang andal, aman dan akrab lingkungan. Namun, sejauh ini belum dikaji bagaimana sistem asesmen terhadap instalatur oleh pejabat teknik dan direktur industri jasa ketenagalistrikan.

Asesmen terhadap instalatur listrik oleh pejabat teknik dan direktur industri jasa ketenagalistrikan, selain digunakan untuk pembinaan, pengembangan karir, juga dapat digunakan sebagai salah satu sumber dalam seleksi tenaga kerja. Hal itu untuk mengidentifikasi tenaga kerja instalatur listrik yang kompeten dan responsif terhadap kinerja perusahaan.

Selden (2011, p.252) menjelaskan bahwa "In exploring performance management, one must start with an explanation of the process of managing individual employee performance. The process of managing individual performance is similar to the models used to manage performance at the organization level". Pengelolaan kinerja berpusat pada individu karyawan. Model-model pengelolaan kinerja yang berpusat pada individu karyawan, mirip dengan pengelola kinerja di tingkat organisasi. Proses pengelolaan dan pengembangan kinerja individu karyawan biasanya dimulai dari pihak atasan atau manager.

Kusrorong (2013, p.6) menjelaskan bahwa kinerja merupakan hasil kerja secara kualitas dan kuantitas yang dapat dicapai oleh seorang pegawai dalam melaksanakan tugas sesuai dengan tanggung jawab yang diberikan kepadanya. Hasibuan (2006, p.34) mengemukakan bahwa kinerja (prestasi kerja) adalah suatu hasil kerja yang dicapai seseorang dalam melaksanakan tugas tugas yang dibebankan kepadanya yang didasarkan atas kecakapan, pengalaman dan kesungguhan serta waktu yang digunakan. Kinerja pada dasarnya merupakan faktor kunci guna mengembangkan suatu perusahaan secara efektif dan efisien, karena adanya kebijakan atau program yang lebih baik atas sumber daya manusia yang ada dalam perusahaan. Kinerja individu sangat bermanfaat bagi dinamika pertumbuhan perusahaan secara keseluruhan.

Marsudi (2012, p.15) menyatakan bahwa "Sistem tenaga listrik yang berfungsi menyediakan tenaga listrik bagi masyarakat pemakai tenaga listrik, secara garis besar terdiri dari instalasi pembangkitan, instalasi penyaluran dan instalasi distribusi yang menuju ke pelanggan ketenagalistrikan". Agar listrik dapat dimanfaatkan pada sisi pemakai tenaga listrik, maka terlebih dahulu dilakukan pekerjaan pengkonstruksian sesuai standar oleh instalatur listrik. Antoni (1995, p.229) menjelaskan bahwa instalatur listrik berasal dari kata "installation", yang artinya adalah perbuatan atau pemasangan dan "electrical' adalah menggunakan tenaga listrik. Jadi, instalatur listrik adalah orang yang memasang pengguna tenaga listrik. Anwir (1983, p.214) menyatakan bahwa instalatur listrik adalah pemasangan, pengikatan, pem- 
bangunan dan penyusunan. Instalatur listrik adalah orang yang bekerja atau ahli memasang instalasi, memasang perlengkapan aliran listrik pada bangunan konsumen.

Staatskoerant (2009, p.3) menjelaskan bahwa "Installation electrician is a person who has been registered as an installation electrician in terms of regulation for the verification and certification of the construction, testing and inspection of any electrical installation, excluding specialist electrical installations. Instalatur listrik (electrician) adalah orang yang telah terdaftar dan bersertifikat Instalatur listrik mengkhususkan diri dalam pekerjaan kabel listrik bangunan, mesin stasioner dan peralatan terkait. Instalatur listrik bekerja sebagai pemeriksaan instalasi listrik, termasuk instalasi listrik khusus. Pekerjaan instalasi terdiri dari; (a) modifikasi atau perbaikan instalasi listrik, (b) koneksi mesin di terminal pasokan mesin tersebut, (c) inspeksi, pengujian dan verifikasi instalasi listrik sesuai standar.

Occinfo $(2009$, p.1) menjelaskan bahwa "Electricians install, alter, repair and maintain electrical systems that are designed to provide heat, light, power, control, signals or fire alarms for all types of buildings, structures and premises". Pendapat ini juga didukung oleh IET (2012, p.5) menyatakan bahwa "Electrical installation work-the design, construction, maintenance, verification and inspection and testing of one or more of the work categories a separate and self-contained premises constructed or adapted to use for residential purposes and forming part of a building from some other part of which it is divided horizontally". Instalatur listrik merupakan orang yang diberi tugas menginstal, mengubah, memperbaiki dan memelihara sistem listrik yang dirancang untuk menyediakan panas, cahaya, listrik, kontrol, sinyal atau alarm kebakaran untuk semua jenis bangunan, struktur dan tempat.

AKLI (2012, p.10) menjelaskan bahwa tenaga kerja konstruksi instalatur listrik harus mempunyai sertifikat keterampilan kerja yang telah memenuhi persyaratan berdasarkan disiplin keilmuan teknik listrik. Penjelasan ini didukung oleh Peraturan Pemerintah Republik Indonesia Nomor 14 Tahun 2012, untuk mewujudkan penyedia- an tenaga listrik yang aman, andal dan ramah lingkungan maka intalasi listrik yang dipasang harus sesuai dengan standar dan tenaga teknik intalatur listrik harus memiliki sertifikat kompetensi. APEI (2008, p.6) menyatakan persyaratan untuk memperoleh sertifikat keterampilan kerja di bidang ketenagalistrikan adalah berijazah Sekolah Menengah Kejuruan program keahlian Teknik Instalasi Tenaga Listrik atau setara. Setelah tenaga instalatur listrik yang bekerja sebagai tenaga pelaksana pada industri jasa konstruksi ketenagalistrikan bersertifikat tenaga kerja terampil, maka instalatur listrik sudah kompeten melakukan pekerjaan mendesain, mengkontruksi, menguji, mengoperasikan dan memelihara instalasi listrik pada konsumen pemakai tenaga listrik.

Scaddan (2005, p.11) menjelaskan "The electrician who is working towards building must be gaining competencies in various aspects of installation work". Aspek yang dimaksud adalah perencanaan, pengkonstruksian, pengujian, pengoperasian dan pemeliharaan instalasi listrik. Seip (2000, p.667) menjelaskan "Planning a building control system is extremely challenging, since it requires experienced planners with expertise in electrical engineering, heating, ventilation, air conditioner and communications technology". Untuk mengerjakan instalasi listrik dibutuhkan tenaga instalatur listrik yang berkompeten di bidangnya, yang telah melewati tahap asesmen kompetensi instalatur listrik (performance assessment) berstandar dan berkualitas (instalatur listrik yang kompeten).

Proses pemanfaatan ketenagalistrikan untuk sampai ke pelanggan membutuhkan tahapan jaringan dan instalasi listrik yang panjang (Marsudi, 2012, p.15). Instalatur listrik sebagai tenaga pelaksana pada industri jasa konstruksi harus selalu ditingkatkan performanya. Aji (2012, p.5) menjelaskan semua peralatan instalasi listrik yang terpasang harus mudah diatur sesuai standar, baik dalam pemeriksaan, pengawasan, pemeliharaan dan perbaikan serta mudah dalam pemasangan dengan memberikan label atau sejenisnya yang menunjukkan penggunaan peralatan tersebut. 
Chani (2000, p.273) menguraikan, untuk mencapai dan menjamin agar pengoperasian sistem ketenagalistrikan menjadi andal, aman, efisien dan ramah lingkungan serta menjamin keselamatan umum, maka diperlukan tenaga pelaksana dan peralatan listrik yang memenuhi ketentuan standar atau mutu yang telah ditetapkan. Subagyo (2009, p.1) menyatakan "Energi listrik memiliki peran yang sangat vital dan strategis". Oleh sebab itu dibutuhkan mutu instalasi listrik yang andal, aman, dan akrab lingkungan dan menjadi persyaratan utama dalam upaya penjaminan ketersediaan energi listrik. Satriya (2012, p.12) menjelaskan perwujudan sistem ketenagalistrikan yang andal, aman, dan ramah (akrab) lingkungan diperoleh jika dikerjakan oleh instalatur listrik yang kompeten.

Murti (2009, p.33) menyatakan instalasi listrik harus andal terhadap perencanaan, mutu peralatan atau komponen instalasi listrik, pengkonstruksian dikerjakan oleh instalatur listrik yang kompeten, pemeriksaan, pengoperasian dan pemeliharaan instalasi listrik sesuai dengan standar. KONSUIL (2010, p.15) mengemukakan data pemasangan instalasi listrik sebanyak 444 di bangunan pelanggan listrik yang telah dilakukan oleh biro instalatur, ternyata hanya 3 pelanggan listrik $(0,45 \%)$ yang Langsung Laik Operasi (LLO), 437 pelanggan listrik (98,42\%) Laik Operasi dengan Catatan (LOC) dan 4 pelanggan listrik $(0,91 \%)$ Tidak Laik Operasi (TLO).

AKLI (2009, p.2) menemukan data, dari 62 sampel pekerjaan Instalatur Listrik, hanya 6 buah $(9,67 \%)$ sampel yang memenuhi kriteria LO. Selebihnya 56 buah (90,33\%) sampel Tidak Laik Operasi (TLO). Data ini menunjukkan keprihatinan peneliti terhadap keingintahuan lebih ilmiah terhadap kesenjangan kompetensi instalatur listrik.

LPJKN (2008, p.2) menjelaskan bahwa "Usaha jasa pelaksana konstruksi adalah jenis usaha jasa konstruksi yang menyediakan layanan jasa pelaksanaan pekerjaan konstruksi, yang dibedakan menurut bentuk usaha, klasifikasi dan kualifikasi usaha jasa pelaksana konstruksi”. Malik (2010, p.15) mengemukakan "Bisnis konstruksi adalah usaha yang dilakukan oleh sekelompok orang untuk mendapatkan sejumlah keuntungan melalui jasa pemborongan di bidang pelaksanaan pekerjaan konstruksi. UndangUndang No. 30 Tahun 2010 meng-uraikan bahwa Usaha jasa penunjang jasa konstruksi meliputi pekerjaan arsitektural, mekanikal, elektrikal, dan tata lingkungan.

Murti (2009, p.44) menyatakan jasa konstruksi nasional masih mempunyai kelemahan dalam manajemen, penguasaan teknologi, dan permodalan, serta keterbatasan tenaga ahli dan tenaga terampil. Jika dianalisis lebih jauh terhadap hasil pekerjaan para instalatur listrik tersebut terdapat kelemahan pada bidang kedisiplinan, kejujuran, integritas, perencanaan, pelaksanakan konstruksi kelistrikan, pengujian, pengoperasian dan pemeliharaan. Inilah kata kunci pengajuan penelitian "Asesmen Intalatur Listrik Berbasis Kebutuhan Indutri Jasa Konstruksi Ketenagalistrikan (AILIS)".

Faktor-faktor yang membangun AILIS terdiri dari; (1) perancangan instalasi listrik (R); (2) pengkonstruksian instalasi listrik (P); (3) komisioning instalasi listrik (K); (4) pengoperasian instalasi listrik $(\mathrm{O})$; dan (5) pemeliharaan instalasi listrik $(\mathrm{H})$. Secara teoretis dapat didekati dengan penjelasan Donald (2010, p.364) dimana, untuk menegaskan atau memeriksa hubungan antara satu set variabel ukur yang dibangun oleh beberapa set faktor-faktor yang lebih kecil dapat menggunakan confirmatory factor analysis (CFA) models. Confirmatory factor analy-sis (CFA) model is used to examine the relationships between a set of measured variables and a smaller set of factors that might account for them. Mengikuti penjelasan tersebut maka, hubungan antara masing-masing faktor bagan konseptual AILIS disajikan pada Gambar 1.

Tujuan penelitian ini adalah menghasilkan asesmen instalatur listrik berbasis industri jasa konstruksi ketenagalistrikan oleh Penanggung Jawab Teknik (PJT) dan direktur perusahaan sebagai penguna informasi atau yang melakukan asesmen. Hasil penelitian AILIS bermanfaat untuk pe- 
ngembangan ilmu asesmen, perbaikan proses pembelajaran pendidikan kejuruan dan pelatihan instalatur listrik di lembaga pendidikan dan lembaga sertifikasi profesi ketenagalistrikan. Sebagai dasar kebijakan pengembangan dan pembinaan karir instalatur listrik di perusahaan jasa konstruksi ketenagalistrikan.

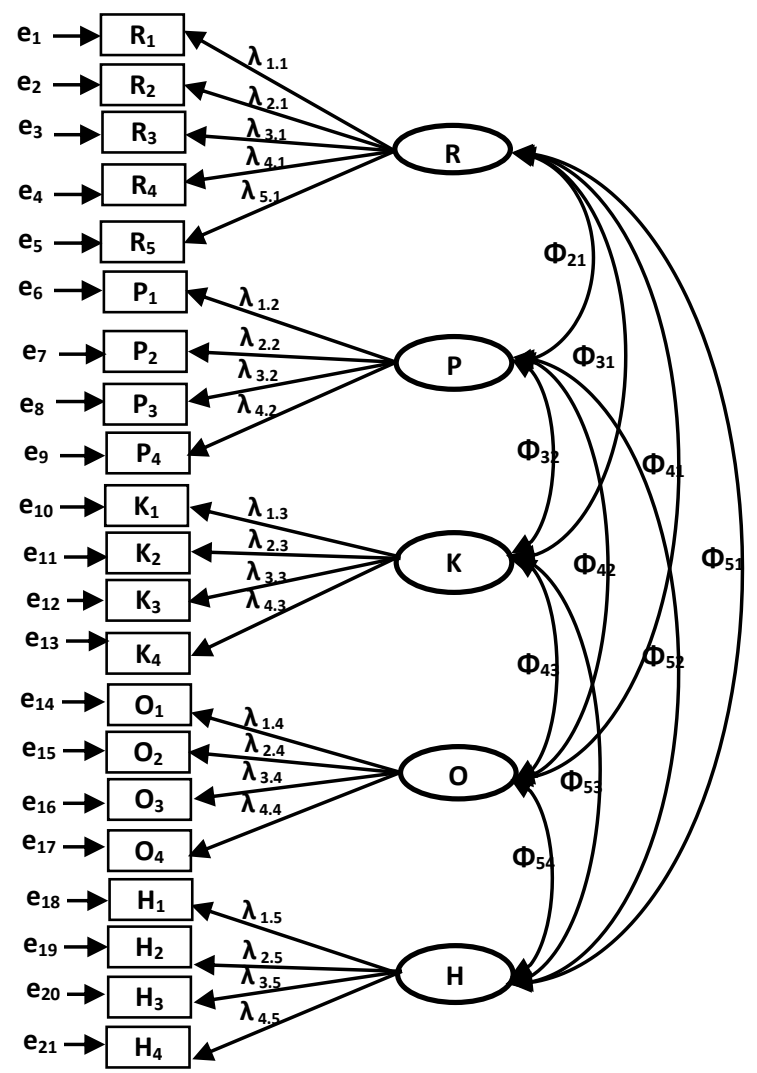

Gambar 1. Bagan Konseptual AILIS (CFA Models)

\section{Metode Penelitian}

Jenis penelitian ini adalah research and development, yang bertujuan menghasilkan produk berupa Asesmen Instalatur Listrik Berbasis Industri Usaha Jasa Konstruksi Ketenagalistrikan (AILIS). Penelitian dan pengembangan AILIS merupakan jenis penelitian yang digunakan untuk memecahkan masalah praktis dan teknis bidang asesmen instalatur listrik di industri usaha jasa konstruksi ketenagalistrikan. Penelitian dan pengembangan AILIS diawali dengan studi pendahuluan, pengembangan, analisis fit dan implementasi AILIS. Secara lengkap tahap- an penelitian dan pengembangan AILIS disajikan Gambar 2.

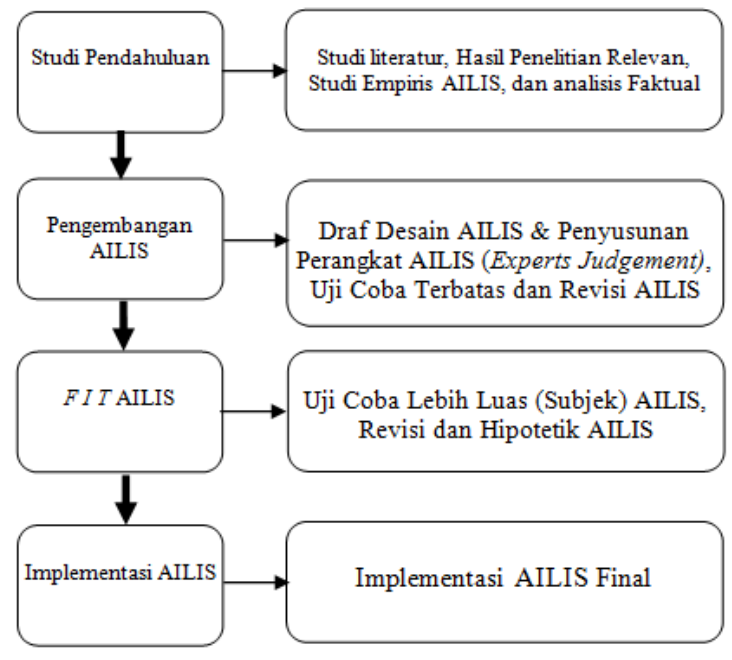

Gambar 2. Tahapan Penelitian AILIS

Penelitian AILIS dilakukan di Provinsi Sumatera Barat, pada bulan Agustus sampai dengan Desember 2014 dengan subjek penelitian adalah para PJT dan direktur industri atau perusahaan jasa konstruksi ketenagalistrikan. Tahap desain adalah validasi 7 orang para pakar bidang teknik elektro, evaluasi atau asesmen, pakar ketenagakerjaan dan pakar di bidang bahasa. Tahap validitas dan reliabilitas asesmen melibatkan 7 orang para pakar di bidangnya dan 35 responden dari pengguna yaitu, pimpinan puncak perusahaan, para manajer yang terkait, para pemegang jabatan bidang ketenagalistrikan (penanggung jawab teknik perusahaan jasa konstruksi ketenagalistrikan). Subjek penelitian tahapan uji coba diperluas adalah 210 responden dari para penanggung jawab teknik dan direktur perusahaan jasa konstruksi ketenagalistrikan.

Instrumen validator para pakar dan pengguna penelitian AILIS dikembangkan sesuai kriteria. Barus (2011, p.35) dan Mardapi (2012, p.86), menjelaskan aspek kualitas konten instrumen terdiri dari; (1) kejelasan petunjuk pengisian instrumen, (2) keluasan cakupan aspek konstruk instrumen, (3) kejelasan indikator setiap aspek, (4) kejelasan rumusan item, (5) kecocokan indikator dengan item, (6) proporsi dan kecukupan jumlah item, (7) kesederhanaan ru- 
musan item, (8) kemudahan pemaknaan/ memahami item, (9) keterbacaan/kemudahan dalam membaca, (10) standar notasi/format huruf dan layout, (11) kemudahan cara menjawab, (12) efisiensi waktu/tenaga dalam mengerjakan, (13) penggunaan bahasa Indonesia yang baku, (14) menghindarkan responden dari pengarahan terselubung, tekanan dan malu dalam menjawab, dan (15) kreativitas penyusunan instrumen untuk memperoleh objektivitas jawaban responden agar terhindar dari bias dan memotivasi responden untuk menjawabnya. Instrumen uji coba diperluas meliputi aspek variabel perancangan, pengkonstruksian, komisioning pengoperasian, dan pemeliharaan instalasi listrik serta dua puluh satu indikator dan 55 item pertanyaan.

Teknik analisis data AILIS menggunakan teknik analisis deskriptif kualitatif dan kuantitatif. Analisis kualitatif meliputi data hasil validitas konten berupa lembaran validator para ahli (Widoyoko, 2013, p.123). Untuk mevalidasi asesmen AILIS, digunakan data empiris yang diperoleh dari hasil pengumpulan data kuantitatif melalui instrumen AILIS. Analisis data uji coba diperluas dengan pendekatan confirmatory factor analysis (CFA). Analisis data kuantitatif dilakukan dengan bantuan software LISREL 8.80 for Windows by Karl G. Jöreskog \& Dag Sörbom (2005). This program is published exclusively by Scientific Software International, Inc. Copyright by Scientific Software International, Inc., 1981-2006. Use of this program is subject to the terms specified in the Universal Copyright Convention. Hasil analisisnya merekombina-sikan AILIS yang memenuhi standar goodness-of-fit atau terstandarisasi (standardized).

\section{Hasil Penelitian dan Pembahasan}

Asesmen Instalatur Listrik Berbasis Industri Usaha Jasa Konstruksi Ketenagalistrikan (AILIS) dikembangkan melalui tiga tahapan, yaitu uji coba awal, uji coba terbatas, dan uji coba diperluas. Setiap tahapan uji coba, responden diminta untuk memberi komentar tentang AILIS. Berdasarkan ketiga tahapan pengembangan tersebut, diperoleh hasil sebagai berikut ini.
Validasi konten instrumen penelitian Asesmen Instalatur Listrik Berbasis Industri Usaha Jasa Konstruksi Ketenagalistrikan dilakukan dengan teknik menyerahkan lembar instrumen penilaian validasi ahli (expert) kepada 7 validator. Lembar instrumen penilaian validasi konten menggunakan skala Likert, yaitu memiliki skala lima tingkat jawaban jenis interval. Yakni $1=$ sangat kurang, $2=$ kurang, $3=$ cukup, $4=$ baik, dan $5=$ sangat baik.

Hasil validasi kualitas konten instrumen AILIS oleh tujuh validator ahli (expert) tersebut tertera pada Tabel 1. Validitas aspek kualitas konten instrumen AILIS oleh ketujuh responden validator ahli (expert) ada pada skor rerata interval >3,4 - 4,2 (klasifikasi baik) dan skor rerata interval $>4,2$ 5,0 (klasifikasi sangat baik).

Interpretasi klasifikasi kualitatif terhadap rerata skor validasi expert dapat merujuk pada penjelasan Widoyoko (2013, p.123) di Tabel 1. Klasifikasi kualitatif rerata skor adalah sangat kurang berada pada interval $(1,0-1,8)$, kurang berada pada interval $(>1,8-2,6)$. Klasifikasi kualitatif cukup dengan rerata skor berada pada interval $(>2,6-3,4)$, baik berada pada interval $(>3,4$ - 4,2) dan sangat baik berada pada interval $(>4,2-5,0)$.

Validasi konten instrumen penelitian Asesmen Instalatur Listrik Berbasis Industri Usaha Jasa Konstruksi Ketenagalistrikan oleh pengguna (user) dilakukan dengan teknik menyerahkan lembar instrumen penilaian validasi pengguna (user) kepada tiga puluh lima (35) validator. Validator pengguna (user) adalah para direktur dan PJT perusahaan usaha jasa konstruksi ketenagalistrikan.

Hasil validasi kualitas konten instrumen AILIS oleh tujuh validator pengguna (user) tersebut tertera pada Tabel 2. Setiap aspek kualitas konten instrumen penelitian AILIS dinilai oleh tiga puluh lima responden pengguna (user). Isi kolom ketiga (jumlah) pada Tabel 2 tersebut adalah jumlah penilaian dari tujuh responden validator pengguna (user). Kolom keempat adalah nilai rerata skor setiap aspek kualitas konten instrumen dari ketujuh responden validator 
pengguna (user) dan seterusnya pada kolom kelima adalah klasifikasi rerata skor. Klasifikasi kualitatif rerata skor adalah sangat kurang berada pada interval $(1,0$ s.d 1,8$)$, kurang berada pada interval (> 1,8 s.d 2,6).
Klasifikasi kualitatif cukup dengan rerata skor berada pada interval (> 2,6 s.d 3,4), baik berada pada interval $(>3,4$ s.d 4,2$)$ dan sangat baik berada pada interval $(>4,2$ s.d 5,0$)$.

Tabel 1. Data Validasi Ahli (Expert) terhadap Kualitas Konten Instrumen AILIS (dilakukan oleh 7 validator expert

\begin{tabular}{|c|c|c|c|c|}
\hline No. & Aspek Kualitas Konten Instrumen & Jumlah & Rerata Skor & Klasifikasi \\
\hline 1. & Kejelasan petunjuk pengisian instrumen. & 34 & 4,9 & Sangat Baik \\
\hline 2. & Keluasan cakupan aspek konstruk instrumen. & 34 & 4,9 & Sangat Baik \\
\hline 3. & Kejelasan indikator setiap aspek. & 28 & 4,0 & Baik \\
\hline 4. & Kejelasan rumusan item. & 33 & 4,0 & Baik \\
\hline 5. & Kecocokan indikator dengan item. & 28 & 4,0 & Baik \\
\hline 6. & Proporsi dan kecukupan jumlah item. & 29 & 4.2 & Baik \\
\hline 7. & Kesederhanaan rumusan item. & 28 & 4,0 & Baik \\
\hline 8. & Kemudahan pemaknaan/memahami item. & 28 & 4,0 & Baik \\
\hline 9. & Keterbacaan/kemudahan dalam membaca. & 35 & 5,0 & Sangat Baik \\
\hline 10. & Standar notasi/format huruf dan layout. & 28 & 4,0 & Baik \\
\hline 11. & Kemudahan cara menjawab. & 28 & 4,0 & Baik \\
\hline 12. & Efisiensi waktu/tenaga dalam mengerjakan. & 35 & 5,0 & Sangat Baik \\
\hline 13. & Penggunaan bahasa Indonesia yang baku. & 28 & 4,0 & Baik \\
\hline 14. & $\begin{array}{l}\text { Menghindarkan responden dari pengarahan terselubung, tekanan, } \\
\text { malu dalam menjawab. }\end{array}$ & 35 & 4,1 & Baik \\
\hline 15. & $\begin{array}{l}\text { Kreativitas penyusunan instrumen untuk memperoleh objektifitas } \\
\text { jawaban responden agar terhindar dari bias dan memotivasi } \\
\text { responden untuk menjawabnya. }\end{array}$ & 29 & 4,1 & Baik \\
\hline & Skor Rerata Total & & 4,3 & Sangat Baik \\
\hline
\end{tabular}

Tabel 2. Data Validasi Pengguna (User) terhadap Kualitas Konten Instrumen AILIS (dilakukan oleh 35 validator $u s e r$ )

\begin{tabular}{clccc}
\hline No. & \multicolumn{1}{c}{ Aspek Kualitas Konten Instrumen } & Jumlah & Rerata Skor & Klasifikasi \\
\hline 1. & Kejelasan petunjuk pengisian instrumen. & 173 & 4,0 & Baik \\
2. & Keluasan cakupan aspek konstruk instrumen. & 172 & 4,9 & Sangat Baik \\
3. & Kejelasan indikator setiap aspek. & 140 & 4,0 & Baik \\
4. & Kejelasan rumusan item. & 140 & 4,7 & Sangat Baik \\
5. & Kecocokan indikator dengan item. & 140 & 4,0 & Baik \\
6. & Proporsi dan kecukupan jumlah item. & 146 & 4,1 & Baik \\
7. & Kesederhanaan rumusan item. & 140 & 4,0 & Baik \\
8. & Kemudahan pemaknaan/memahami item. & 140 & 4,0 & Baik \\
9. & Keterbacaan/kemudahan dalam membaca. & 175 & 5,0 & Sangat Baik \\
10. & Standar notasi/format huruf dan layout. & 140 & 4,0 & Baik \\
11. & Kemudahan cara menjawab. & 141 & 4,0 & Baik \\
12. & Efisiensi waktu/tenaga dalam mengerjakan. & 175 & 5,0 & Sangat Baik \\
13. & Penggunaan bahasa Indonesia yang baku. & 141 & 4,0 & Baik \\
14. & Menghindarkan responden dari pengarahan & 144 & 5,0 & Sangat Baik \\
& terselubung, tekanan, malu dalam menjawab. & & & Baik \\
15. & Kreativitas penyusunan instrumen untuk & & & Sangat Baik \\
& terhindar dari bias dan memotivasi responden & 142 & 4,1 & \\
$\quad$ untuk menjawabnya. & & & \\
& $\quad$ Skor Rerata Total & 4,3 & & \\
\hline
\end{tabular}


Hasil analisis validitas instrumen penelitian Asesmen Instalatur Listrik Berbasis Kebutuhan Industri Usaha Jasa Konstruksi Ketenagalistrikan dengan menggunakan teknik koefisien validitas isi (content validity coefficient)-Aiken's $\mathrm{V}$ expert dan user didapatkan hasil seperti Tabel 3. Koefisien validitas isi Aiken's V expert dan user adalah 0,929 dan 0,976, angka ini menunjukkan instrumen penelitian ALIS adalah valid. Artinya instrumen penelitian AILIS adalah valid digunakan oleh PJT dan direktur di industri usaha jasa konstruksi ketenagalistrikan. Hasil analisis reliabilitas instrumen penelitian Asesmen Instalatur Listrik Berbasis Kebutuhan Industri Usaha Jasa Konstruksi Ketenagalistrikan dengan menggunakan teknik reliabilitas inter rater (ICC) didapatkan hasil seperti Tabel 4, bahwa koefisien reliabilitas ICC expert adalah 0,811. Hasil yang didapat koefisien reliabilitas ICC user adalah 0,847 yang menunjukkan konsitensi kesepakatan antarrater adalah tinggi. Artinya instrumen penelitian AILIS reliabel digunakan oleh PJT dan direktur di industri usaha jasa konstruksi ketenagalistrikan.

Tabel 3. Rekapitulasi Hasil Analisis Koefisien Validitas Konten Aiken's V Expert dan User terhadap Kualitas Konten Instrumen AILIS

\begin{tabular}{llc}
\hline No Validator & $\begin{array}{c}\text { Koefisien } \\
\text { Aiken's V }\end{array}$ & Klasifikasi \\
\hline 1. Ahli (Expert Judgement) & 0,929 & Valid \\
2. Pengguna (User) & 0,976 & Valid \\
\hline
\end{tabular}

Tabel 4. Rekapitulasi Hasil Analisis Koefisien Reliabilitas Inter Rater Expert dan User terhadap Kualitas Konten Instrumen AILIS

\begin{tabular}{lcc}
\hline No Validator & $\begin{array}{c}\text { Koefisien } \\
\text { Reliabilitas ICC }\end{array}$ & Klasiikasi \\
\hline 1. Ahli (Expert Judgement) & 0,811 & reliabel \\
2. Pengguna (User) & 0,847 & reliabel \\
\hline
\end{tabular}

Hasil uji coba instrumen Asesmen Instalatur Listrik Berbasis Industri Usaha
Jasa Konstruksi Ketenagalistrikan secara keseluruhan variabel laten yang diarahkan kepada indikator masing-masing variabel manifes setelah mengikuti saran LISEL. Yaitu posisi modification indices pada path diagram, yang dianalisis dengan CFA menggunakan bantuan software LISREL 8.80 diperoleh asesmen yang fit (Gambar 3 dan 4). Yaitu: (1) Chi-Square < $2 d f(206,06<356,0)$ dimana degree of freedom ( $d f=178,00)$, (2) $\mathrm{P}$ value $=0,07350>0,05 ;$ dan 3). Root Mean Square Error of Approximation (RMSEA) $=$ $0,026<0,0$.

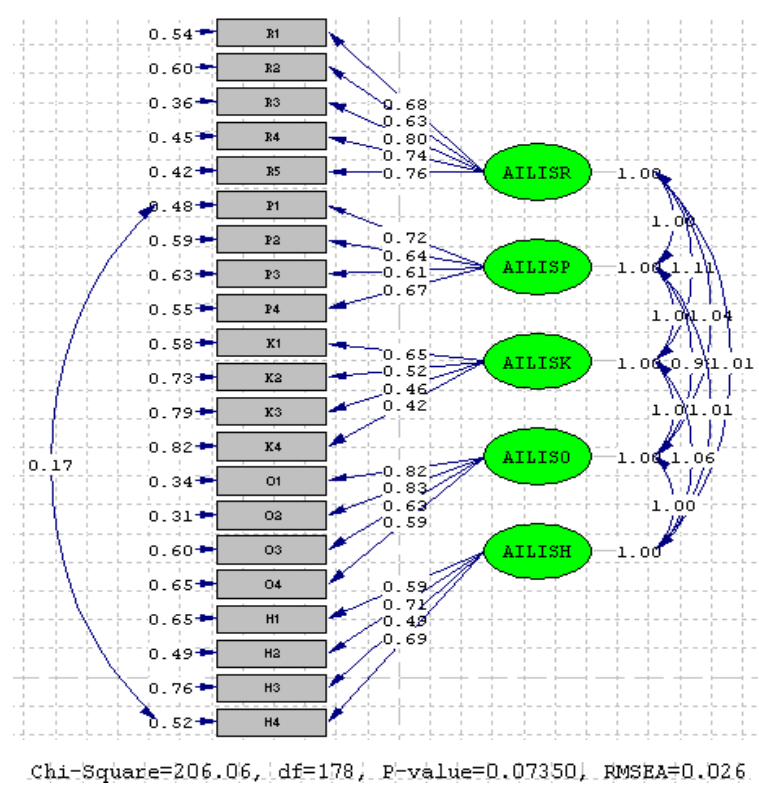

Gambar 3. Hasil Uji coba AILIS (Posisi Standardized)

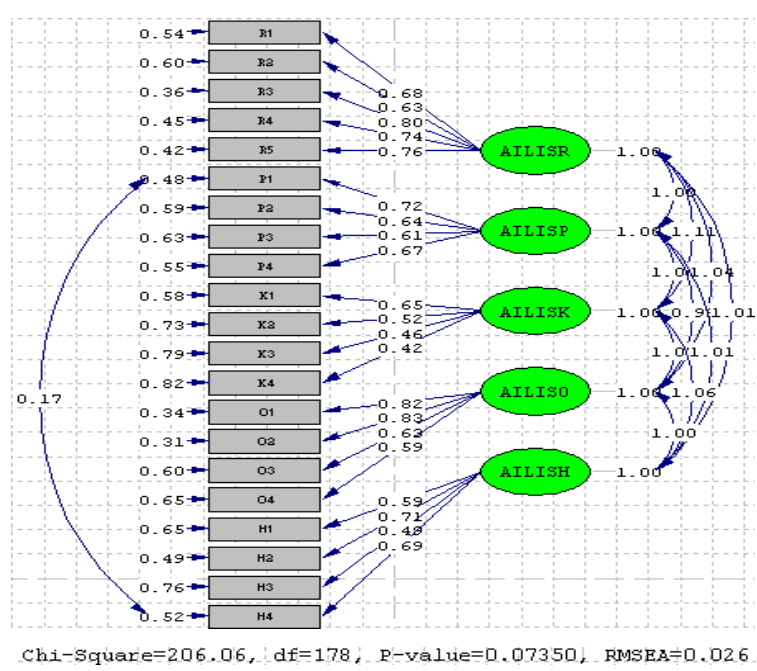

Gambar 4. Hasil Uji coba AILIS (Posisi T-values) 
Hasil uji coba instrumen Asesmen Instalatur Listrik Berbasis Industri Usaha Jasa Konstruksi Ketenagalistrikan secara keseluruhan variabel laten yang diarahkan kepada indikator masing-masing variabel manifes memenuhi kriteria goodness-of-fit models. Hasil ini menyatakan bahwa instrumen Asesmen Instalatur Listrik Berbasis Industri Usaha Jasa Konstruksi Ketenagalistrikan secara keseluruhan memiliki lima variabel laten yaitu perancangan instalasi listrik, pengkonstruksian instalasi listrik, komisioning instalasi listrik, pengoperasian instalasi listrik, dan pemeliharaan instalasi listrik.

Variabel laten perancangan instalasi listrik (AILISR) berkorelasi dengan variabel manifes pengukurnya yaitu merancang peralatan sistem listrik tiga fase berdaya kecil dan besar $\left(\mathrm{R}_{1}\right)$, memodifikasi peralatan dan sistem pengawatan instalasi listrik $\left(\mathrm{R}_{2}\right)$, merancang instalasi listrik dan sistem pencahayaan $\left(\mathrm{R}_{2}\right)$, merancang sistem proteksi kelistrikan $\left(\mathrm{R}_{2}\right)$, dan merancang instalasi listrik kawasan bahaya dan energi terbarukan $\left(\mathrm{R}_{5}\right)$.

Variabel laten pengkonstruksian instalasi listrik (AILISP) berkorelasi dengan variabel manifes pengukurnya yaitu melaksanakan persiapan pekerjaan di tempat kerja $\left(\mathrm{P}_{1}\right)$, melaksanakan pengelolaan teknis di tempat kerja $\left(\mathrm{P}_{2}\right)$, memasang peralatan listrik dan elektronik $\left(\mathrm{P}_{3}\right)$, dan memasang instalasi listrik daerah berbahaya $\left(\mathrm{P}_{4}\right)$. Variabel laten komisioning instalasi listrik (AILISK) berkorelasi dengan variabel manifes pengukurnya yaitu komisioning peralatan fungsional dan sirkuit sederhana $\left(\mathrm{K}_{1}\right)$, komisioning sirkuit kompleks dan peralatan instalasi listrik $\left(\mathrm{K}_{2}\right)$, komisioning instalasi listrik yang berpotensi menimbulkan ledakan $\left(\mathrm{K}_{3}\right)$, dan komisioning instalasi listrik sistem energi terbarukan $\left(\mathrm{K}_{4}\right)$.

Variabel laten pengoperasian instalasi listrik (AILISO) berkorelasi dengan variabel manifes pengukurnya yaitu mengoperasikan peralatan pengalih daya listrik sesuai tegangan $\left(\mathrm{O}_{1}\right)$, mengoperasikan genset $\left(\mathrm{O}_{2}\right)$, mengoperasikan mesin produksi $\left(\mathrm{O}_{3}\right)$, dan mengoperasikan unit pemanas dan pendingin $\left(\mathrm{O}_{4}\right)$. Variabel laten pemeliharaan instalasi listrik (AILISH) berkorelasi dengan variabel manifes pengukurnya yaitu pemeliharaan peralatan listrik rumah tangga $\left(\mathrm{H}_{1}\right)$, pemeliharaan panel listrik dan peralatan proteksi $\left(\mathrm{H}_{2}\right)$, pemeliharaan perangkat instalasi penerangan dan rangkaian $\left(\mathrm{H}_{3}\right)$, dan pemeliharaan peralatan mesin-mesin listrik dan perlengkapan pelindung bahaya $\left(\mathrm{H}_{4}\right)$.

\section{Pembahasan}

Berdasarkan Tabel 1, 2 dan 3, masih terdapat validitas aspek kualitas konten instrumen AILIS dengan skor rerata interval $>$ 3,4-4,2 (klasfikasi baik). Hal ini berarti bahwa belum semua kelima belas aspek kualitas konten instrumen AILIS memiliki validitas skor rerata interval $>4,2-5,0$ (klasifikasi sangat baik). Oleh sebab itu perlu ada revisi aspek kualitas konten instrumen AILIS yang berklasifikasi baik menjadi sangat baik, berdasarkan saran dari validator expert dan user agar dapat diteruskan pada uji coba terbatas.

Berdasarkan saran perbaikan dari validator expert bidang bahasa Indonesia tentang tatatulis kalimat instrumen penelitian AILIS. Perbaikan pada bagian kejelasan dan indikator instrumen yang direvisi adalah petunjuk pengisian dan isi instrumen. Datadata yang diberikan oleh Direktur atau PJT perusahaan usaha jasa konstruksi ketenagalistrikan di Provinsi Sumatera Barat dalam instrumen penelitian sangat dijaga kerahasiaan. Direktur atau PJT perusahaan usaha jasa konstruksi ketenagalistrikan dibolehkan tidak menyebut nama responden dan nama perusahaan secara spesifik. Peneliti sangat memerlukan kejujuran dan keikhlasan responden memberikan asesmen secara objektif terhadap Instalatur listrik yang ada di perusahaa. Direktur atau PJT dimohon untuk memberikan pernyataan terhadap setiap pernyataan sesuai dengan kondisi di perusahaan.

Validator expert bidang evaluasi dan asesmen menyarankan perbaikan pernyataan kriteria dan kreativitas penyusunan instrumen penelitian AILIS. Revisi terhadap kejelasan kriteria item instrumen, yakni, menggunakan skala Likert yang memiliki skala lima tingkat jawaban jenis interval. 
Direktur atau PJT menilai tenaga kerja instalatur listrik berklasifikasi sangat baik (skor 5), apabila menunjukkan kinerja yang konsisten, memenuhi kriteria kinerja terkait dengan konsep pekerjaan instalasi listrik. Penyelesaian pekerjaan, menggunakan teknik, prosedur, informasi dan sumber-sumber yang ada di tempat kerja. Hal itu menunjukkan pemahaman yang sangat baik terhadap pengetahuan pendukung instalasi listrik sesuai standar PUIL 2000 dan Amandemen 2006.

Menilai tenaga kerja Instalatur listrik berklasifikasi baik (skor 4), bila memenuhi kriteria kinerja terkait dengan konsep instalasi listrik. Penyelesaian pekerjaan, menggunakan teknik, prosedur dan sumber-sumber yang ada di tempat kerja. Pemahaman yang baik terhadap pengetahuan pendukung instalasi listrik. Penilaian tenaga kerja Instalatur listrik berklasifikasi cukup (skor 3), apabila dapat melaksanakan pekerajaan instalasi listrik sesuai dengan tempat kerja dan teori pendukungnya melalui pendampingan dari atasan. Penilaian tenaga kerja Instalatur listrik berklasifikasi kurang (skor 2), apabila melaksanakan pekerajaan instalasi listrik tidak sesuai standar. Penilaian tenaga kerja Instalatur listrik berklasifikasi sangat kurang (skor 1), apabila tidak mampu melaksanakan pekerajaan instalasi listrik.

Perbaikan instrumen penelitian AILIS yang berasal dari saran validator expert bidang teknik elektro, vokasional dan ketenagakerjaan adalah pemenuhan kecukupan instrumen penelitian AILIS merangkum keseluruhan pekerjaan instalasi listrik. Pekerjaan merancang, mengkonstruk, mengkomisioning, mengoperasi dan memelihara instalasi listrik. Perbaikan yang berasal dari validator pengguna (user) adalah kemudahan dan kesederhanan dalam menjawab pernyataan instrumen penelitian AILIS.

Hasil revisi aspek kualitas konten instrumen AILIS berdasarkan saran validator expert dan user tentang faktor kejelasan indikator, rumusan, kecocokan indikator, dan kecukupan jumlah item instrumen. Kesederhanaan rumusan, kemudahan pemaknaan, standar notasi atau format huruf dan layout item instrumen. Kemudahan cara menjawab item instrumen dan penggunaan bahasa Indonesia yang baku. Kemampuan item instrumen menghindarkan responden dari pengarahan terselubung, tekanan, malu dalam menjawab. Kreativitas penyusunan instrumen untuk memperoleh objektifitas jawaban responden agar terhindar dari bias dan memotivasi responden untuk menjawab. Selanjutnya, instrumen penelitian AILIS dapat diteruskan kepada tahapan uji coba terbatas, untuk memperoleh tingkat reliabilitas dan validitas instrumen.

Berdasarkan hasil analisis inter rater dalam bentuk koefisien konsistensi antarpenilai atau intraclass correlation coefficient (ICC) oleh validator expert dan user terhadap aspek kualitas konten instrumen AILIS adalah 0,811 dan 0,847. Koefisien Aiken's V expert $=0,929$ dan user $=0,976$. Perolehan angka koefisien reliabilitas inter rater dan koefisien Aiken's $\mathrm{V}$ yang demikian membuktikan bahwa terdapat konsistensi antarpenilai kualitas konten instrumen penelitian AILIS yang signifikan. Instrumen AILIS dinyatakan reliabel atau andal digunakan lebih lanjut oleh direktur dan PJT perusahaan usaha jasa konstruksi ketenagalistrikan.

Berdasarkan hasil uji reliabilitas dan validitas item instrumen asesmen Intalatur Listrik Berbasis Kebutuhan Industri Jasa Konstruksi dengan taraf kepercayaan 95\% diperoleh koefisien Aiken's V 0,976 atau valid. Hal ini menunjukkan nilai reliabilitas dan validitas yang signifikan. Dengan demikian, instrumen penelitian AILIS reliabel dan valid digunakan oleh direktur dan PJT perusahaan usaha jasa konstruksi ketenagalistrikan.

Nilai kesesuaian instrumen asesmen Instalatur Listrik Berbasis Industri Usaha Jasa Konstruksi Ketenagalistrikan: (1) ChiSquare $<2 d f(206,06<356,00)$ dimana degree of freedom ( $d f=178,00)$, (2) P-value $=0,0735$ $>$ 0,05; dan (3) Root Mean Square Error of Approximation $($ RMSE $A)=0,026<0,05$. Hasil analisis tersebut menunjukkan bahwa, berdasarkan tahap uji coba diperluas kedua puluh satu indikator instrumen Asesmen Instalatur Listrik Berbasis Industri Usaha 
Jasa Konstruksi Ketenagalistrikan. Lima puluh lima item instrumen Asesmen Instalatur Listrik Berbasis Industri Usaha Jasa Konstruksi Ketenagalistrikan memenuhi kriteria goodness-of-fit models.

Semua indikator instrumen Asesmen Instalatur Listrik Berbasis Industri Usaha Jasa Konstruksi Ketenagalistrikan termasuk valid karena nilai muatan faktor $(\lambda)$ lebih besar dari 0,3. Karena semua persyaratan sebagai asesmen yang fit terpenuhi. Instrumen Asesmen Instalatur Listrik Berbasis Industri Usaha Jasa Konstruksi Ketenagalistrikan tersebut sudah dapat digunakan sebagai AILIS yang sesuai untuk mengumpulkan data tentang kinerja Instalatur listrik.

\section{Simpulan dan Saran}

Simpulan

Penelitian Asesmen Instalatur Listrik Berbasis Industri Usaha Jasa Konstruksi Ketenagalistrikan dikembangkan melalui tiga tahapan, yaitu uji coba awal, uji coba terbatas, dan uji coba diperluas. Berdasarkan hasil analisis data, penelitian Asesmen Instalatur Listrik Berbasis Industri Usaha Jasa Konstruksi Ketenagalistrikan ini dapat disimpulkan sebagai berikut.

Pertama, berdasarkan hasil penilaian para ahli dan praktisi, panduan instrumen dan rubik asesmen instalatur listrik berbasis kebutuhan industri jasa konstruksi ketenagalistrikan merupakan panduan dan rubrik yang jelas, sederhana, sangat mudah dipahami, komunikatif, efisien, dan mudah digunakan.

Kedua, berdasarkan hasil penilaian para ahli dan pengguna serta hasil uji statitstik, instrumen-instrumen yang dikembangkan dalam penelitian asesmen instalatur listrik berbasis kebutuhan industri jasa konstruksi ketenagalistrikan merupakan instrumen yang dapat menghasilkan hasil pengukuran yang valid dan reliabel.

Ketiga, AILIS dinilai sebagai asesmen yang sangat baik untuk mengakses kinerja Instalatur listrik di industri jasa konstruksi ketenagalistrikan, karena terdapat kesesuaian Asesmen Instalatur Listrik Berbasis Kebutuhan Industri Jasa Konstruksi Ketenaga- listrikan dengan data lapangan, yang menunjukkan bahwa AILIS fit, dengan indikator perancangan, pengkonstruksian, komisioning, pengoperasian, dan pemeliharaan instalasi listrik.

Saran

Saran pemanfaatan, diseminasi, dan pengembangan poduk lebih lanjut meliputi. Pertama, AILIS agar dijadikan sebagai alternatif pilihan pertama bagi direktur dan penanggung jawab teknik (PJT) untuk mengakses tenaga kerja instalatur listrik di lingkungan perusahaan industri usaha jasa konstruksi ketenagalistrikan. Kedua, AILIS dapat dikembangkan lebih lanjut berupa program komputer (softwre), aplikasi yang beroperasi melalui instruksi yang dijalankan dengan menggunakan komputer, sehingga seorang asesor dapat menganalisis data secara cepat dan akurat. Ketiga, AILIS dapat dikembangkan dengan cara memanfaatkan sistem information and technology (IT) yang diintegrasikan dengan jaringan telekomu-nikasi. Agar data hasil asesmen kinerja instalatur listrik di lokasi pekerjaan mudah diakses oleh operator IT perusahaan. Keempat, AILIS dimasukkan sebagai konten materi pembelajaran mata kuliah evaluasi pendidikan dan instalasi listrik di Jurusan Teknik Elektro Fakultas Teknik Universitas Negeri Padang.

\section{Daftar Pustaka}

Adnan, A., Hussain, I., Ahmed, S., \& Akbar, M.F. (2010). Performance Appraisals Impact on Attitudinal Outcomes and Organisational Performance. Interna-tional Journal of Business and Management Vol. 5, No. 10; October 2010, 62-75.

Amandemen PUIL. (2006). Amandemen Persyaratan Umum Instalasi Listrik (PUIL) 2000. Jakarta: Panitia Revisi PUIL.

Antoni, A. (1995). Kamus Lengkap Teknik Inggris-Indonesia. Surabaya: Gitame-dia press. 
Anwir, B.S. (1983). Kamus Teknik (Cetakan Ketujub). Jakarta: PT. Pradnya Paramita.

Aji, D.A. (2012). Instalasi listrik. (online), (http://www.slideshare. net/fearzie13/ insta-lasilistrikirdamaraji, akses 15 Juni 2012).

Asosiasi Kontraktor Listrik dan Mekanikal Indonesia (AKLI) Cabang Bukittinggi (2009). Laporan Hasil Survei Tahun 2009. Bukitinggi: Dewan Pengurus Asosiasi Kontraktor Listrik dan Mekanikal Indonesia (AKLI) Cabang Bukittinggi.

Asosiasi Kontraktor Listrik dan Mekanikal Indonesia-AKLI. (2012). Regulasi Berkaitan dengan Keberadaan AKLI. Jakarta: Asosiasi Kontraktor Listrik dan Mekanikal Indonesia.

Asosiasi Profesionalis Elektrikan dan Mekanikal Indonesia-APEI. (2008). Buku Pedoman Ujian Sertifikat Keterampilan Kerja. Jakarta: Asosiasi Profesionalis Elektrikan dan Mekanikal Indonesia.

Barbara, E., \& Walvoord. (2010). Assessment Clear and Simple, Second Edition. San Francisco: John Wiley \& Sonc, Inc.

Barus, G. (2011). Pengembangan Instrumen Asesmen Kebutuhan Perkembangan untuk Penyusunan Kurikulum dan Evaluasi Program BK. Jurnal Penelitian dan Evaluasi Pendidikan Tahun 15, Nomor 1, 2011, 2246.

Berry, B., \& Adamson. (2011). Assessment Reform in Education Policy and Practice. New York: Springer Science Business Media B.V.

Chani, A. (2000). Peranan Sertifikasi untuk Peralatan Listrik. Proceedings Forum Studi Tegangan Tinggi Antar Universitas. Seminar Nasional dan Workshops Tegangan Tinggi III. ISBN: 979-96249-08. Kampus UI-Depok 20-21 Nopember 2000, 272-275.

David, D.G. (2006). Designing a competency based program to facilitate the progression of experienced engineering technologists to professional engineer status. European journal of engineering education, 31 (1). pp. 95-107.

Devan, J. (2013). Doing Business 2013 Smarter Regulations for Small and Medium-Size Enterprises. Comparing Business Regulations for Domestic Firms In 185 Economies $\left(10^{\text {th }}\right.$ Edition). Washington: International Finance Corporation (IFC).

Dewan Perwakilan Rakyat RI. (2009). Undang-Undang No.30 Tabun 2009 tentang, Ketenagalistrikan. Jakarta: Dewan Perwakilan Rakyat RI.

Elaine, D.P. (2004). Performance Management A roadmap for deve-loping, implementing and evaluating performance management systems. Colorado: SHRM Foundation All rights reserved.

Hasibuan, M.S.P. (2006). Manajemen Sumber Daya Manusia Dasar dan Kunci Keberbasilan (Edisi Revisi). Jakarta: Bumi Aksara.

Idemobi, E.I., Onyeizugbe., \& Chinedu. (2011). Performance Management as an Imperative for Effective Performance in Delta State of Nigerian Public Owned Organizations. Sacha Journal of Policy and Strategic Studies, Volume 1 Number 2 (2011), p. 46-54.

IET. (2012). Electrotechnical Assessment Specification for Use By Certification And Registration Bodies. The International Electrotechnical Commi-ssion-EAS 12-304, Institution of Engineering and Technology (IET).

Jöreskog, K.G. \& Sörbom, D. (2005). LISREL for Windows [Computer Software]. Lincolnwood, IL: Scientific Software International, Inc.

Kementerian Sekretariat Negara RI. (2012). Peraturan Pemerintah Republik Indonesia RI Nomor 14 Tahun 2012, tentang Kegiatan Usaha Penyediaan Tenaga Listrik. Jakarta: Kementerian Sekretariat Negara RI. 
Komite Keselamatan Untuk Instalasi Listrik-KONSUIL. (2010). Perlu Mewaspadai Instalasi Listrik Rumah. Jurnal Nasional, p.16.

Kusrorong, R.P.B. (2013). Penyelenggaraan Pemerintahan dalam Pelayanan dan Kebijakan Publik Terkait dengan Aspek. Ham dan Kesejabteraan. Diakses tanggal 3 Mei 2014 dari http://ejournal.unsrat. ac.id/index.php/governance/article/ 1036/838.

Lee, F.K. (2000). Using the Five-Factor Model (FFM) of Personality to Enhance Career Development and Organizational Functioning in the Workplace. Journal of Career Assessment. Volume 8. Number 4, 419-427.

Leila, N., Yadollah, H., \& Ghiansi, M. (2011). Performance Evaluation and its Effects on Employees' Job Motivation in Hamedan City Health Centers. Australian Journal of Basic and Applied Sciences, 5(12): 1761-1765.

Lembaga Pengembangan Jasa Konstruksi Nasional. (2008). Registrasi Usaha Jasa Pelaksana Konstruksi. Jakarta: Dewan Pengurus Lembaga Pengembangan Jasa Konstruksi Nasional.

Lembaga Pengembangan Jasa Konstruksi Provinsi Sumatera Barat. (2013). Data Badan Usaba Jasa dan Konstruksi Provinsi Sumatera Barat Tahun 2013. Padang: Dewan Pengurus Lembaga Pengembangan Jasa Konstruksi Provinsi Sumatera Barat.

Lynn, C. (2005). Senior Management Perceptions of Project Management Competence. International Journal of Project Management 23 (2005) 7-16.

Malik, A. (2010). Pengantar Bisnis Jasa Pelaksana Konstruksi. Yogyakarta. C.V Andi Offset.

Mardapi, D. (2011). Penilaian Pendidikan Karakter. Yogyakarta. Universitas Negeri Yogyakarta.
Mardapi, D. (2012). Pengukuran Penilaian \& Evaluasi Pendidikan. Yogjakarta: Nuha Medika.

Marsudi, D. (2012). Masalah Konstruksi, Operasi, dan Pemeliharaan dalam Sistem Tenaga Listrik. Jurnal Konduktif Volume I, April 2012, 15-18.

Messah, O., \& Bernard. (2011) The Effect of Performance Appraisal Systems on Employees in Kenya Tea Development Agency: A Survey of Selected Tea Factories in Meru County-Kenya. Research Journal of Finance and Accounting Vol 2, No 3, 16-34.

Murti, S. (2009). Ketenagalistrikan Indonesia. Jakarta: Jakarta: Kemen-terian Energi Dan Sumber Daya Mineral.

Obisi, C. (2011). Employee Performance Appraisal and Its Implication for Individual and Organizational Growth. Australian Journal of Business and Management Research Vol.1, No.9, December 2011, 92-97.

Occinfo. (2009). The Alberta Learning Information Service (ALIS). Alberta: Human Services. Diakses tanggal 15 Mei 2011 dari http://alis.albertacal occinfo/content/ requestaction.asp? aspaction=gethtml profile \&oformat= htmlevoccpro id $=71003081$.

Padmadewi, N., \& Nyoman. (2005). Asesmen Berbasis Kompetensi: Aplikasinya Dalam Pembelajaran Keterampilan Berbicara. Jurnal Pendidikan dan Pengajaran IKIP Negeri Singaraja, No. 3 TH. XXXVIII Juli 2005, 455-472.

PUIL. (2000). Persyaratan Umum Instalasi Listrik (PUIL) 2000. Jakarta: Panitia Revisi PUIL.

Satriya, A. (2012). Peranan APEI dalam Mewujudkan Instalasi Tenaga Listrik yang Andal, Aman dan Akrab Lingkungan. Jurnal Konduktif Volume I, April 2012, 12-16.

Scaddan, B. (2005). Electrical Installation Work (Fifth Edition). London: British 
Library Cataloguing in Publication Data.

Seip, G.G. (2000). Electrical Installations Handbook $\left(3^{\text {th }} e d\right)$. Munich Germany: Publicis MCD Werbeagentur GmbH.

Selden, S., \& Sowa, J.E. (2011). Performance Management and Appraisal in Human Service Organizations: Management Public Personnel Management, DOI: 10.1177/009102601104000305, Volume 40 No. 3 Fall 2011.

Staatskoerant. (2009). Occupational Health and Safety Act Electrical Installation Regulations. Department of Labour, Gover- ment Notices, No.31975, 6 March 2009.

Subagyo, H. (2009). Kapita Selekta, Realita dan Problema Dunia Usaba Jasa Konstruksi. Jakarta: Pengurus Pusat Asosiasi Profesionalis Elektrikal Indonesia.

Widoyoko, P. E. (2013). Teknik Penyusunan Instrumen Penelitian. Yogyakarta: Pustaka Pelajar.

Wy1nne \& Sharon, M.S. (2008). Reading Instruction Competence Assessment. Melrose: Xamonline, Inc. 